\title{
The benefits of eHRM and Al for talent acquisition
}

\author{
Richard D. Johnson, Dianna L. Stone and Kimberly M. Lukaszewski
}

\author{
Richard D. Johnson is \\ based at the Department of \\ Management, Information \\ Systems, and \\ Entrepreneurship, \\ Washington State \\ University, Pullman, \\ Washington, USA. \\ Dianna L. Stone is based at \\ the Departments of \\ Managment at the \\ University of New Mexico \\ and Virginia Tech, San \\ Antonio, TX, USA. \\ Kimberly M. Lukaszewski is \\ based at the Department of \\ Management and \\ International Business, \\ Wright State University, \\ Dayton, Ohio, USA.
}

Received 7 February 2020 Revised 26 May 2020 Accepted 26 May 2020

(C) Richard D. Johnson, Dianna L. Stone and Kimberly M. Lukaszewskid.Published in the Journal of Tourism Futures. Published by Emerald Publishing Limited. This article is published under the Creative Commons Attribution (CC BY 4.0) license. Anyone may reproduce, distribute, translate and create derivative works of this article (for both commercial and non-commercial purposes), subject to full attribution to the original publication and authors. The full terms of this license may be seen at http://creativecommons.org/licences/by/4.0/ legalcode

This paper forms part of a special section "The future of e-HRM and Artificial Intelligence in the hospitality \& tourism industry", guest edited by Dr Huub Ruel.

\begin{abstract}
Purpose - The hospitality and tourism industry faces a number of workforce challenges, especially the high turnover rates and associated replacement costs associated with continually identifying and hiring new employees. The purpose of this paper is to discuss how hospitality and tourism organizations can use electronic human resource management (eHRM) and artificial intelligence (AI) to help recruit and select qualified employees, increase individual retention rates and decrease the time needed to replace employees. Specifically, it discusses how e-recruiting and e-selection and Al tools can help hospitality and tourism organizations improve recruiting and selection outcomes.
\end{abstract}

Design/methodology/approach - Research on eHRM, Al, employee recruitment and employee selection are applied to the hospitality and tourism industry and insights for how eHRM and Al can be applied to the industry are discussed.

Findings - eHRM and Al have the potential to transform how the hospitality and tourism industry recruit and select employees. However, care must be taken to ensure that the insights gained and the decisions made are well received by employees and lead to better employee and organizational outcomes.

Research limitations/implications - This paper represents the first research that integrates research from eHRM and $\mathrm{Al}$ and applies it to the hospitality and tourism industry.

Originality/value - This paper represents the first research that integrates research from eHRM and Al and applies it to the hospitality and tourism industry.

Keywords Selection, Artificial intelligence, Recruitment, e-HRM, Electronic human resource management, eHRM, Employee selection, e-recruiting, e-selection

Paper type Research paper

$\square$ ike all industries, the hospitality and tourism industry faces a number workforce challenges. For instance, the hospitality industry is labor intensive, with estimates suggesting that hoteliers spend approximately $33 \%$ of revenue on labor costs (Deloitte, 2015). One of the primary labor challenges is the very high turnover rate in the industry. Estimates indicate that the turnover rate for the hospitality industry in the USA is over $50 \%$, with some sectors (e.g. hotel and food) experiencing turnover rates of over $70 \%$ (Bureau of Labor Statistics, 2019). These estimates are similar to those found in other countries, such as the UK (30\%) (KPMG, 2019) and The Netherlands (30\%) (Vellenga, 2016). In addition, these turnover rates have been growing for the past 10 years (Bureau of Labor Statistics, 2019). Turnover also has a dramatic impact on labor costs, with a recent industry survey suggesting $41 \%$ of organizations found that an entry-level hire who subsequently leaves could cost the organization over \$30,000 (McConway, 2019).

Thus, a great deal of time and money are spent attracting new applicants, and dealing with the "churn in the system" associated with constantly replacing employees. We believe that electronic human resource management (eHRM) and artificial intelligence (AI) can help the industry reduce this turnover rate, and ensure that they can attract, motivate and retain talented employees. For instance, the use of electronic recruitment (e-recruitment) and electronic selection (e-selection) methods can help companies in the industry uncover 
talented applicants, and hire those that fit with the requirements of jobs (P-J fit) and organizations (P-O fit) (Kristof-Brown, 2000). Increased job and organizational' fit should enable organizations to hire talented employees, reduce attrition rates, and decrease the heavy time and workload associated with the constantly replacing employees (Johnson and Stone, 2019; Kristof-Brown, 2000).

We believe that eHRM and Al can be beneficial for hospitality organizations and enable them to hire talented employees, or decrease the time needed to replace them. In particular, we consider how the use of e-recruitment can help attract and uncover qualified applicants who will join and remain with the organization, and e-selection can help organizations increase the level of fit between applicants and jobs or organizations so that they will remain with the organization. However, we first consider the overall goals of the HR systems in organizations as well as a brief overview of eHRM and Al. We then turn to a discussion how they can enhance recruitment and selection practices. We then briefly close by noting the risks and concerns to consider when implementing Al-enabled eHRM in recruitment and selection.

\section{Goals of human resource management systems in organizations}

The primary goals of the HR system in organizations are to attract, motivate and retain talented employees (Katz and Kahn, 1978). Research on HR strategy has revealed that employees are more important than ever in today's service and knowledge organizations because companies compete on the basis of the talents and skills of their employees (Huselid, 1995). To achieve these goals, HR systems must be designed to meet several key objectives (Johnson and Stone, 2019; Stone et al., 2003). For example, they should attract highly talented applicants by using effective recruiting practices. In addition, they must use selection systems to hire the best applicants and ensure that there is a fit between individuals and jobs and the goals of organizations. Further, they need to offer training and development opportunities as job requirements change. Finally, they should enhance the retention of workers through effective selection and compensation systems. However, if retention rates are low, high turnover rates often create a "churn" in the system, which means that organizations are constantly involved in the hiring and replacement process.

\section{Electronic human resource management}

There is no question that technology is transforming the practice of human resources. From recruitment to retirement, employees interact with, and are affected by, human resource information systems (HRIS). An HRIS is "used to acquire, store, manipulate, analyze, retrieve, and distribute information regarding an organization's human resources." (Kavanagh and Johnson, 2018, p. 8) and has altered the way we recruit, select, train, compensate employees and develop HR strategies (Parry and Tyson, 2008; Strohmeier, 2007). In fact, the increased use of HRIS has provided HR with the information that allows them to transform HRM policies and practices (Johnson et al., 2016). This new approach to managing HRM has been called electronic human resource management (eHRM) and is defined as the use of internet or intranet technology to facilitate human resource management (HRM) processes including recruitment, selection, training, performance management, compensation and HR planning (Lengnick-Hall and Moritz, 2003; Ruël et al., 2004). For example, Web-based recruitment, online testing, e-learning and electronic compensation each represent a form of eHRM (Johnson et al., 2016), and research has shown that eHRM can improve HR outcomes (Bondarouk and Ruël, 2013; Parry and Tyson, 2008). With the increased use of eHRM, large organizations are now turning to Al to enhance decision-making and communication. 


\section{Artificial intelligence}

In 1950, Alan Turing proposed that humans would consider a machine intelligent if the human interacting with that machine could not tell whether he or she was interacting with a human or a machine (Turing, 1950). Subsequently, cognitive scientists, computer scientists and others have attempted to design intelligent systems. These intelligent, or artificial intelligence (Al), systems were originally designed to mimic human cognitive decision processes, and to support and solve a well-defined or structured problems. The earliest systems focused on solving "common sense" problems using algorithmic logic (McCarthy, 1958). Not surprisingly, Al often refers to a class of technologies, whose goal is to replicate human cognitive processing (Flasiński, 2016).

With the global deployment of information systems and the growth in organizational understanding of business processes, organizations continue to explore ways to improve decision-making, prediction and performance (Dulebohn and Johnson, 2013; von Krogh, 2018). Core to these advances in decision-making capabilities is the use of $\mathrm{Al}$, which the Society of Human Resource Management (SHRM) has identified as one of its top technology trends and a key driver of HRM in the future (Wright, 2017). However, for the hospitality industry to leverage fully $\mathrm{Al}$ to support $\mathrm{HR}$, they will need to understand both their core industry, as well as how technology and statistics can improve decision-making (Maurath, 2014).

Al provides capabilities that support three areas of business functioning (Davenport and Ronanki, 2018). First, Al can enhance business process automation by providing cognitive capabilities within the software. For example, organizations are using $\mathrm{Al}$ to augment automated decision-intensive tasks such as loan processing and supply chain management, and provide cognitive insights about customer purchasing behavior. In support of HRM, the National Aeronautics and Space Administration (NASA) found that the use of Al enhanced HR processes allowed them to complete $86 \%$ of HR tasks without human intervention (Davenport and Ronanki, 2018). In a sense, with Al-enabled process automation the software algorithmically makes and implements decisions with little human intervention. Given that researchers have found that Al-based expert systems can mimic the decision recommendations of employee benefits experts (Sturman et al., 1996), Alenabled eHRM would not simply recommend a set of benefits from which employees can choose, but would choose these benefits for employees, and automatically sign them up.

Second, Al can provide cognitive insights that facilitates decision-making. This form of Al uses algorithms and machine learning to interpret vast amounts of data, looking for hidden patterns not previously identified by organizations. Organizations have used Al in this fashion to predict customer-purchasing behavior, identify fraud and create customized advertisements. For example, in the last two presidential election cycles, candidates used Al to target messages to unique groups of individuals to maximize the impact of each ad and reduce costs (Smith, 2018). In addition, Al was able to more accurately diagnose cancer patients, and to do so in a fraction of the time needed by a panel of medical experts (Miller, 2019). Al has also helped assess the link job characteristics to employee satisfaction (Tian and $\mathrm{Pu}, 2008$ ).

Finally, using intelligent agents and chatbots, Al can support cognitive engagement. These agents are the closest thing to Al as theorized by Turing, because the goal of chatbots and intelligent agents is to retrieve and share knowledge from a knowledge base, and share that with individuals through natural and human-like social interaction. One of the reasons for deploying chatbots in organizations is to handle the ever-increasing number of applicant, employee and customer requests for information. For example, many e-commerce vendors deploy intelligent agents to help customers make purchase decisions (Xiao and Benbasat, 2007), and organizations are starting to use chatbots to help customers and employees. For example, SEBank uses an intelligent chatbot to provide support for employees that have IT- 
related questions (Davenport and Ronanki, 2018). We now turn to a discussion about how eHRM- and Al-enabled eHRM can improve recruitment and selection outcomes in the hospitality industry.

\section{E-recruitment}

Organizational recruitment is driven by the goal of attracting highly qualified individuals and motivating them to apply for jobs (Breaugh and Starke, 2000; Rynes, 1991). If organizations are able to attract a large pool of qualified applicants, they can then be selective in the hiring process, and hire the best individuals for their jobs. To accomplish these goals, organizations have started using electronic recruiting (e-recruiting) methods. E-Recruiting is:

the use of communications technologies, such as websites and social media, to find and attract potential job applicants, to keep them interested in the organization during the selection processes, and to influence their job choice decisions (Chapman and Gödöllei, 2017, p. 213).

The use of e-recruitment has several advantages for hospitality organizations including broadening the applicant pool, and increasing the efficiency of the recruitment process (Chapman and Gödöllei, 2017). In addition, the use of Al-enabled e-recruitment methods can enhance recruitment outcomes including initial screening. Each of these are discussed below.

\section{Broadening the applicant pool}

Given the large turnover rates in the hospitality and tourism industry, these organizations regularly need to identify and attract a large number of applicants to fill critical job vacancies. By listing openings on recruitment websites, applicants can easily access them any time of the day or night. Organizations have found that the use of e-recruitment has led to a much larger applicant pool than traditional recruitment processes (Chapman and Gödöllei, 2017). For example, Kia Motors received 43,000 applications within 30 days for 2500 open positions when they opened a new plant in Georgia (Adams, 2008). In addition, increasing the size of the applicant pool will also increase the likelihood that organizations will uncover individuals who fit the desired hospitality-oriented and organizational specific values and goals. Recruiting individuals that fit with organizational goals should increase the likelihood that they will accept jobs, and remain with the organization over time (Cable and Judge, 1997).

Al can also help enlarge the applicant pool and attract applicants who fit with the organization. Specifically, organizations can use Al cognitive insight capabilities to identify the characteristics of high performing employees and those who have remained with the organization for a long time. For example, some research has shown that employee needs for good relationships with co-workers and supervisors, job enrichment, developmental opportunities and satisfaction with pay influence retention rates (Hom and Griffeth, 1995). Organizations can then identify the characteristics of high performing employees, including those who have remained with the organization for a long time, and develop targeted recruitment messages that can motivate similar applicants to apply for jobs.

\section{Reaching passive job applicants}

Another major advantage of e-recruiting is that organizations can identify and attract applicants who may be currently employed, and not actively seeking another job (i.e. passive applicants). For example, organizations can scan professional social media sites (e.g. Linkedln) to uncover individuals who meet job requirements, and contact the person about applying for a job. One benefit of identifying passive applicants is that they may already have the needed job experience and should be less likely to be job hoppers. 
Research has found that using professional social media sites such as Linkedln were very effective in identifying and attracting qualified job applicants (Nikolaou, 2014).

Using data stored in the HRIS, organizations can also scan the employee records of current employees to identify those who meet the requirements of the positions. A major advantage of this approach is that current employees may gain promotion opportunities, and the process may lead other employees to believe that the company offers advancement opportunities, which should increase job satisfaction rates. Although this strategy appears feasible, we know of no research that has examined its effectiveness.

\section{Enhancing efficiency and timeliness: reducing costs of recruitment}

The use of e-recruiting can also increase the efficiency and timeliness of recruitment, and decrease recruitment costs (Stone et al., 2005). For example, research has found that erecruitment can decrease recruiting costs by $95 \%$ and hiring cycles by $25 \%$ (Cober et al., 2000). Although e-recruiting can increase the administrative burden associated with processing large number of applicants, the automated processes associated with erecruiting can also streamline processes. For instance, e-recruiting can use keyword scanning systems to determine if applicants meet minimum job requirements, and quickly send letters to applicants relaying their status in the screening process (Johnson and Stone, 2019; Stone et al., 2003). In addition, online applications allow applicants to input their work history, education, personal information, and other job-related details requested by the organization. Software can then automatically scan the application or resume and use keywords to determine if applicants are qualified for jobs.

One of the biggest challenges facing organizations is identifying highly qualified applicants from their large pools (Ideal, 2019). Al-enabled process automation can assist with this step by using algorithms to identify profiles of talented applicants and select the ones who should be invited for interviews. Al can also generate letters to applicants indicating if they are qualified or not qualified for jobs, and provide them with information about the next steps in the process (Stone et al., 2005). The standardization of the initial screening process can improve its efficiency, enhance the fairness of the process and ensure that organizations recruit the most effective applicants (Stone et al., 2005; Sylva and Mol, 2009). This can also have a positive impact on applicants' motivation to apply for jobs because research has shown that applicants are more likely to apply for jobs in organizations with good rather than poor administrative processes (Rynes, 1991).

Another major challenge in the recruitment process is communicating with applicants, and ensuring that they are aware of their status in the process. Industry research found that $43 \%$ of applicants never heard back from an organization after their initial contact (Workopolis, 2016), and the lack of information created negative reactions to the organization. Chatbots connected to an organization knowledge base can help by automatically responding to simple inquires and informing them about their status. This can improve applicant perception $s$ of the firm and reduce negative applicant reactions.

\section{Increasing applicant attraction and degree of fit assessments}

Another benefit of e-recruiting is that websites can be designed to increase applicants' attraction to an organization and recruitment messages can be tailored to target applicants with specific skill levels. Research has found that applicants were more attracted to jobs when their cultural values were consistent with the values and goals of the organization displayed on the website (Harrison and Stone, 2018). Other research indicated that applicants were more likely to apply for jobs when the website revealed job-related and benefits information than when it did not (Allen et al., 2007). Further research revealed that applicants were more satisfied with websites that were customized for specialized openings than those that were not (Furtmüller et al., 2010). 
In addition, research indicated that a number of website characteristics had a positive impact on applicant attraction to organizations including website usability (Cober et al., 2003); website speed and ease of use (Sinar et al., 2003); and the aesthetic design of the website (Murphy et al., 2018). However, it is important to note that the research on website aesthetics is inconsistent. Some studies, Cober et al. (2003), found that website aesthetics were not related to applicants' organizational attraction, but others indicated that they were related to applicants' attraction (Murphy et al., 2018). Thus, additional research is needed to understand fully which website characteristics can enhance applicants' motivation to apply for jobs.

Recruiting websites can also help potential applicants assess their P-O fit before applying for jobs (Dineen et al., 2002), which should enhance the degree that they will remain with the organization (Dineen and Noe, 2009). For example, hospitality and tourism organizations can design websites to display employee testimonials about the pride that they feel when they provide outstanding customer service and enable people have extremely memorable holidays. Websites can also provide applicants with a realistic job previews (RJP), which are messages about the pros and cons of working for the organization. In particular, comments might indicate that working in the organization can be extremely satisfying and involves interaction with customers from around the world. However, the comments can also specify that interactions with customers may be difficult and stressful, and it can be hard to please all individuals. Some recent research examined a new strategy that organizations are using to increase the degree to which websites provide personalized information to applicants. In particular, a study by Harrison and Stone (2018) examined the degree to which "contacting a friend at the organization" enhanced applicant attraction and found that this strategy was effective for applicants who were high rather than low in collectivism.

Although we know of no specific research on the use of RJPs in the e-recruiting process, we believe that the use of online RJPs can increase employees' satisfaction rates, and reduce turnover levels. The primary reason for this that applicants can self-select themselves out of the selection process if they feel that they do not fit with the job or organization (Hom et al., 1998; Wanous, 1978). This strategy can be extremely beneficial for hospitality organizations because it is likely to decrease the relatively high turnover rates in the industry. However, research is needed to examine its effectiveness.

Al can also enhance the effectiveness of e-recruiting. For example, companies can use Al to develop games that help prospective applicants understand what it is like to work for the organization, and can help them assess the extent to which their personality or values matches those in the organization. For example, Shell created a game that allows players to explore for oil, and Siemens created a game that allows individuals to practice managing a plant (Smurthwaite, 2019). Results showed that these games increased the extent to which high fit employees applied for jobs with the companies.

Taken together, the brief review above suggested that e-recruiting and Al can help organizations broaden their applicant pool; reach passive job applicants; increase the timeliness and efficiency of the recruiting process; enhance applicants' attraction to organizations; and improve the degree to which applicants can assess fit with the organization. In the paragraphs that follow, we consider how e-selection may be beneficial to hospitality organizations.

\section{E-selection}

As noted above, we believe that e-selection can also help hospitality organizations hire and retain talented employees. Two factors thought to influence individuals' retention in organization are the degree to which they fit with the job requirements, and fit with the goals and values of the organization (Cascio, 2019). Quite simply, when individuals' knowledge, 
skills, abilities and other requirements (KSOAs) correspond to the requirements of the job (P-J fit), their performance should be higher, and they should have more positive job attitudes toward the organization than when their KSAOs do not match job requisites (Chatman, 1989; Kristof-Brown, 2000). It merits noting that research has shown consistently that individuals' job satisfaction levels are related positively to retention in organizations (Griffeth et al., 2000). Further, models of person organization fit (Chatman, 1989; KristofBrown, 2000) also predict that when individuals' values are congruent with the goals and values of the organization they are more likely to accept a job and remain with the organization than when their values are not in agreement with organizational values (Cable and Judge, 1997). In support of these arguments, research on P-J fit and P-O fit found that perceptions of organizational fit were positively related to job satisfaction and organizational commitment and were negatively related to turnover (Verquer et al., 2003).

Given that individuals' P-J and P-O fit are likely to increase retention levels, we believe that methods used to increase the degree of fit between individuals and jobs or organizations should help hospitality organizations decrease their turnover rates. We also maintain that the use of e-selection systems and Al may enable organizations to increase P-J and P-O fit levels. Thus, in the sections that follow we consider how e-selection systems might assist organizations in enhancing the fit between employees and jobs and/or the overall organizational goals.

\section{Simplifying job analysis}

One of the first steps in the selection process is conducting a job analysis, which identifies task requirements and uncovers the KSAOs (job specifications) needed to perform the job (Gatewood et al., 2016). Although organizations use a variety of techniques to conduct job analyses (e.g. questionnaires, interviews), the process can be very time-consuming, and we believe that the use of online job analysis will greatly simplify and streamline this process. For example, an online job analysis typically gives job analysts the opportunity to collect data from subject matter experts (SMEs) (e.g. job incumbents and supervisors) about job requirements and specifications using Internet questionnaires. In turn, the responses are shared electronically with a panel or group of analysts (Gatewood et al., 2016). This panel can meet using videoconferencing to discuss task requirements and develop a job description without traveling to remote locations. They can also make inferences about job specifications (e.g. KSAOs) in a virtual environment.

Thus, an electronic job analysis approach uses geographically dispersed SME panels to discuss and make final decisions about job requirements and job specifications. The identification of tasks and KSAOs is important for every aspect of HRM, but is especially important in the recruitment and selection process. Organizations use data from a job analysis to develop recruiting websites and is the basis for initial screening criteria and selection decisions (Stone et al., 2013). Although there has been relatively little research on the effectiveness of this process, a study by Reiter-Palmon et al. (2006) found that electronic job analysis methods were less time-consuming, more flexible and easier to use than traditional methods. Thus, organizations can identify the job-related tasks and specifications quickly using an online job analysis technique that reduces the time needed for the overall selection process.

Al can also support electronic job analysis in several ways. First, Al can help job analysts develop job descriptions and specifications. For example, Al could parse any previous descriptions for positions, match them with job descriptions for external positions or from systems such as O*Net[1]. Thus, Al could be used in the first step of job analysis and help analysts understand the nature of the job and skill requirements prior to collecting data from SMEs. These data could also be used to develop job analysis questionnaires. Second, organizations could use Al to update job descriptions so that they match the job that is currently being done by employees. Over time, job descriptions and specifications can 
become outdated, and Al could be used to scan existing job descriptions and identify parts that need to be updated.

\section{Facilitating online employment testing}

Another major advantage of e-selection is that it can facilitate the employment testing process (e.g. cognitive ability testing, personality inventories), and use the information to determine the degree of fit between individuals and jobs or organizations (Stone et al., 2013). For instance, organizations can test applicants remotely, using the internet, and applicants can complete employment tests or inventories at remote locations at their convenience (Tippins et al., 2006). This process enhances the timeliness and flexibility associated with employment testing, and decreases the need for test proctors, which decreases the overall costs of testing.

There has been some research on the equivalence of computerized or internet-based cognitive ability tests, and in- person testing, but the results of this research have been mixed (Stone et al., 2013). One of the major questions addressed by this research is whether computerized and paper and pencil cognitive ability tests generate comparable test scores. Some research has found that the two forms of the tests are equivalent (Buchanan and Smith, 1999), but other studies revealed that scores for online ability tests were lower and more variable than those for paper and pencil tests (Ployhart et al., 2003; Potosky and Bobko, 2004). Thus, organizations may not want to use online cognitive ability tests until strategies are developed to ensure that the two forms of tests provide comparable results.

Although online and paper and pencil cognitive ability tests may not always be equivalent, research has shown that computerized and paper versions of personality inventories are equivalent in most cases (Chuah et al., 2006; Salgado and Moscoso, 2003). Thus, organizations may be able to use online personality inventories in the selection process, and use the information to make key hiring decisions. Some research has revealed that the use of personality inventories may not always be predictive of job performance (Johnson and Stone, 2019), but other research has shown that matching an applicants' personality to the values of the organization enhances P-O fit (Cable and Judge, 1997). Thus, we believe that hospitality organizations might want to use personality inventories to increase their retention rates because an extraversion and agreeable may be related to good customer service. Research, however, is needed to examine this prediction.

Al can also facilitate selection in several ways. For example, Al-enabled business process automation can be used to develop computer adaptive tests (CAT) which tailor test items to each test taker (Tippins et al., 2006). CAT is designed so that when test takers answer a question it is tailored to the person's skill level, and when questions are answered correctly a more difficult test items is presented. However, when a question is answered incorrectly, an easier question is presented. Thus, Al can help organizations develop targeted tests based upon test takers' skill level and an analysis of the answering patterns. This approach can maintain the validity of the tests and reduce test administration time and costs (Overton et al., 1997).

\section{Enabling remote video interviewing}

Another advantage of using e-selection is that it lets organizations interview applicants at remote locations and decreases the costs and time associated with the interview process (Stone et al., 2013). For example, organizations can now use videoconferencing to conduct pre-employment interviews. As evidence of the popularity of video interviewing, over 80 companies currently offer video-based interviewing solutions (Software Advice, 2019). These interviews can be two-way (i.e. interviewee and interviewer can communicate with one another) or one-way (i.e. interviewee answers questions only). With two-way interviews, 
organizations can use a video-conferencing tool such as Zoom or Skype to interview an applicant. With a one-way interview, or digital interview an individual might respond to a predetermined set of questions on videoconferencing (Kharkovyna, 2018). These interviews should be especially helpful for hospitality organizations because they will enable decision makers to determine the degree to which individuals' fit job requirements and ascertain if applicants' values are congruent with the organizational values. For example, excellent customer service is often a major value in hospitality organizations, and interviewers can ask applicants to provide situational examples of the time they provided excellent customer service in their previous jobs. Applicants' responses to this question and others should help decision makers determine if there is a good fit between the applicants' and organization's goals.

There are a number of ways that $\mathrm{Al}$ can improve online interviews. First, setting up interviews can be time-consuming and cumbersome. Chatbots (using cognitive engagement) can automatically handle the scheduling and coordination of interviews with candidates, including any updates regarding future meetings and locations (Kharkovyna, 2018). Research has found that $66 \%$ of candidates were comfortable using chatbots in this way. In addition, Al can support the analysis of digital interviews. Organizations are using Al-enabled business process automation to automatically analyze muscular contractions (e.g. frowning while talking about prior employment), voice tone (e.g. enthusiastic about this position or company), and proficiency in English from the video interview (Kharkovyna, 2018). Finally, Al has the potential as a coaching tool for applicants. It is likely that mentors and coaches will work with individuals to improve their interviewing skills, and can use these same tools to provide feedback to their mentees.

\section{Supporting effective selection decision-making}

The last step in the selection process is to combine all of the information collected in the process to make a final selection decision. For example, organizations can merge information gathered from job applications, employment tests, personality inventories and interviews, and Al can develop algorithms that weight and combine the information to make overall hiring recommendations. The use of Al should be very beneficial in this process because it does not include biases or affect reactions to applicants, which often mislead decision-making. Thus, we believe that the use of Al algorithms may make more effective selection decisions than traditional decision-making, but research is needed to examine this prediction. Industry research supports this argument, finding that Al enabled hiring decisions result in a $20 \%$ increase in employee performance and a $35 \%$ decrease in turnover rates (Ideal, 2019). Overall, we believe that e-selection and Al can help hospitality organizations hire employees with a better P-O fit and increase retention rates. We identified a number of benefits of using e-selection and Al-enabled hiring decisions including simplifying job analysis, facilitating employment testing, enabling remote video interviewing and supporting overall selection decisions.

\section{Conclusion}

The hospitality and tourism industry is a labor-intensive industry that faces a number of important workforce challenges. Chief among them is the high level of turnover in the field. As a result, we argued that eHRM and Al could help them attract, motivate and retain talented employees, and reduce turnover rates. In this paper, we considered how the use of eHRM and Al may enhance the fit between employees and organizations, and increase retention rates. As Johnson et al. (2016) noted, the very act of automating HR practices provides organizations with additional capabilities that enable them to hire the most talented employees who will be motivated to remain with the organization over time. 


\section{Note}

1. O*Net is an online database of occupations developed by the US Government, which lists KSAs needed, work activities and more that are associated with different positions (www.onetonline.org/).

\section{References}

Adams, T. (2008), "Kia receives 43,000 applications for west point auto plant", available at: www.ledgerenquirer.com/news/local/article28988608.html (accessed 4 May 2019).

Allen, D.G., Mahto, R.V. and Otondo, R.F. (2007), "Web-based recruitment: effects of information, organizational brand, and attitudes towards website on applicant attraction", Journal of Applied Psychology, Vol. 92 No. 6, pp. 1696-1708.

Bondarouk, T. and Ruël, H. (2013), "The strategic value of e-HRM: results from an exploratory study in a governmental organization", The International Journal of Human Resource Management, Vol. 24 No. 2, pp. 391-414.

Breaugh, J.A. and Starke, M. (2000), "Research on employee recruitment: so many studies, so many remaining questions", Journal of Management, Vol. 26 No. 3, pp. 405-434.

Buchanan, T. and Smith, J.L. (1999), "Using the internet for psychological research: personality testing on the world-wide web", British Journal of Psychology, Vol. 90 No. 1, pp. 125-144.

Bureau of Labor Statistics (2019), "Job openings and labor turnover survey (JOLTS)", available at: www. bls.gov/jtt/\#data (accessed 2 May 2019).

Cable, D.M. and Judge, T.A. (1997), "Interviewers' perceptions of person-organization fit and organizational selection decisions", Journal of Applied Psychology, Vol. 82 No. 4, pp. 546-561.

Cascio, W.F. (2019), Managing Human Resources, 11th ed., McGraw-Hill, New York, NY.

Chapman, D.S. and Gödöllei, A.F. (2017), "E-recruiting: using technology to attract job applicants", in Hertel, G., Stone, D., Johnson, R.D. and Passmore, J. (Eds), The Wiley Blackwell Handbook of the Psychology of the Internet at Work, Wiley Blackwell, Hoboken, pp. 211-230.

Chatman, J.A. (1989), "Improving interactional organizational research: a model of person-organization fit", Academy of Management Review, Vol. 14 No. 3, pp. 333-349.

Chuah, S.C., Drasgow, F. and Roberts, B.W. (2006), "Personality assessment: does the medium matter?", Journal of Research in Personality, Vol. 40 No. 4, pp. 359-376.

Cober, R.T., Brown, D.J., Blumental, A.J., Doverspike, D. and Levy, P. (2000), "The quest for the qualified job surfer: it's time the public sector catches the wave", Public Personnel Management, Vol. 29 No. 4, pp. 479-496.

Cober, R.T., Brown, D.J., Levy, P.E., Keeping, L.M. and Cober, A.L. (2003), "Organizational web sites: web site content and style as determinants of organizational attraction", International Journal of Selection and Assessment, Vol. 11 Nos 2/3, pp. 158-168.

Davenport, T.H. and Ronanki, R. (2018), "Artificial intelligence for the real world", Harvard Business Review, Vol. 96 No. 1, pp. 108-116.

Deloitte (2015), "Hospitality 2015", available at: www2.deloitte.com/ie/en/pages/consumer-business/ articles/hospitality-2015.html (accessed 3 May 2019)

Dineen, B.R., Ash, S.R. and Noe, R.A. (2002), "A web of applicant attraction: person-organization fit in the context of web-based recruitment”, Journal of Applied Psychology, Vol. 87 No. 4, pp. 723-734.

Dineen, B.R. and Noe, R.A. (2009), "Effects of customization on application decisions and applicant pool characteristics in a web-based recruitment context", Journal of Applied Psychology, Vol. 94 No. 1, pp. 224-234.

Dulebohn, J.H. and Johnson, R.D. (2013), "Human resource metrics and decision support: a classification framework", Human Resource Management Review, Vol. 23 No. 1, pp. 71-83.

Flasiński, M. (2016), Introduction to Artificial Intelligence, Springer International Publishing, Switzerland.

Furtmüller, E., Wilderom, C. and Van Dick, R. (2010), "Sustainable e-recruiting portals: how to motivate applicants to stay connected throughout their careers?", International Journal of Technology and Human Interaction, Vol. 6 No. 3, pp. 1-20. 
Gatewood, R.D., Field, H.S. and Barrick, M. (2016), Human Resource Selection, 8th ed., Cengage, Mason, $\mathrm{OH}$.

Griffeth, R.W., Hom, P.W. and Gaertner, S. (2000), "A meta-analysis of antecedents and correlates of employee turnover: update, moderator tests, and research implications for the next millennium", Journal of Management, Vol. 26 No. 3, pp. 463-488.

Harrison, T. and Stone, D.L. (2018), "Effects of organizational values and employee contact on erecruiting", Journal of Managerial Psychology, Vol. 33 No. 3, pp. 311-324.

Hom, P. and Griffeth, R. (1995), Employee Turnover, Southwestern, Cincinnati, OH.

Hom, P.W., Griffeth, R.W., Palich, L.E. and Bracker, J.S. (1998), "An exploratory investigation into theoretical mechanisms underlying realistic job previews", Personnel Psychology, Vol. 51 No. 2, pp. 421-451.

Huselid, M.A. (1995), "The impact of human resource management practices on turnover, productivity, and corporate financial performance", Academy of Management Journal, Vol. 38 No. 3, pp. 635-672.

Ideal (2019), "Al for recruiting: a simple guide for HR professionals", available at: https://ideal.com/airecruiting/ (accessed 3 May 2019).

Johnson, R.D., Lukaszewski, K.M. and Stone, D.L. (2016), "The evolution of the field of human resource information systems: co-evolution of technology and HR processes", Communications of the Association for Information Systems, Vol. 38 No. 28, pp. 533-553.

Johnson, R.D. and Stone, D.L. (2019), "Advantages and unintended consequences of using electronic human resource management (eHRM) processes", in Landers, R. (Ed.), Cambridge Handbook of Technology and Employee Behavior, Cambridge University Press, Cambridge, UK, pp. 879-920.

Johnson, R.D., Thatcher, J.B. and Burleson, J. (2016), "A framework and research agenda for studying eHRM: automating and informating capabilities of HR technology", Research in Human Resource Management: Human Resource Management Theory and Research on New Employment Relationships, Information Age, Charlotte, NC.

Katz, D. and Kahn, R.L. (1978), The Social Psychology of Organizations, Wiley, New York, NY.

Kavanagh, M.J. and Johnson, R.D. (2018), Human Resource Information Systems: Basics, Applications, and Future Directions, 4th ed., Sage Publications, Thousand Oaks, CA.

Kharkovyna, O. (2018), “Al is your new HR”, available at: https://medium.com/@oleksii_kh/hr-is-yournew-hr-5-example-of-using-machine-learning-in-human-resources-a380ef4a77ff (accessed 7 May 2019).

KPMG (2019), "Labour migration in the hospitality sector", available at: www.bha.org.uk/wordpress/wpcontent/uploads/2017/05/BHA-EU-migration-final-report-170518-public-vSTC.pdf (accessed 10 May 2019).

Kristof-Brown, A.L. (2000), "Perceived applicant fit: distinguishing between recruiters' perceptions of person-job and person-organization fit", Personnel Psychology, Vol. 53 No. 3, pp. 643-671.

Lengnick-Hall, M.L. and Moritz, S. (2003), "The impact of e-HR on the human resource management function", Journal of Labor Research, Vol. 24 No. 3, pp. 365-379.

McCarthy, J. (1958), "Programs with common sense", National Physical Laboratory proceedings in Teddington, Teddington, November.

McConway, J. (2019), "The cost of 'bad hires' in the hospitality industry", available at: www.4hoteliers. com/features/article/12176

Maurath, D. (2014), "A critical incident for big data", The IndustriaL-Organizational Psychologist, Vol. 51 No. 3, pp. 15-25.

Miller, T. (2019), The New World of Human Resources and Employment: How Artificial Intelligence and Process Redesign is Driving Dramatic Change, Business Express Press LLC, New York, NY.

Murphy, S.A., Fisher, P.A., Keeping, L.M. and Brown, D.J. (2018), "Pounding the pavement in the 21st century: a review of the literature regarding organizational recruiting websites", in Dulebohn, J.H. and Stone, D.L. (Eds), The Brave New World of eHRM 2.0, Information Age Publishing, Charlotte, NC, pp. 11-46.

Nikolaou, I. (2014), "Social networking web sites in job search and employee recruiting", International Journal of Selection and Assessment, Vol. 22 No. 2, pp. 179-189. 
Overton, R.C., Harms, H.J., Taylor, L.R. and Zickar, M. (1997), “Adapting to adaptive testing”, Personnel Psychology, Vol. 50 No. 1, pp. 171-185.

Parry, E. and Tyson, S. (2008), "An analysis of the use and success of online recruitment methods in the UK", Human Resource Management Journal, Vol. 18 No. 3, pp. 257-274.

Ployhart, R.E., Weekley, J.A., Holtz, B.C. and Kemp, C. (2003), "Web-based and paper-and-pencil testing of applicants in a proctored setting: are personality, biodata, and situational judgment tests comparable?", Personnel Psychology, Vol. 56 No. 3, pp. 733-752.

Potosky, D. and Bobko, P. (2004), "Selection testing via the internet: practical considerations and exploratory empirical findings", Personnel Psychology, Vol. 57 No. 4, pp. 1003-1034.

Reiter-Palmon, R., Brown, M., Sandall, D.L., Buboltz, C. and Nimps, T. (2006), "Development of an O*NET web-based job analysis and its implementation in the US Navy: lessons learned", Human Resource Management Review, Vol. 16 No. 3, pp. 294-309.

Ruël, H., Bondarouk, T. and Looise, J.K. (2004), "E-HRM: innovation or irritation; an explorative empirical study in five large companies on web-based HRM", Management Revue, Vol. 15 No. 3, pp. 364-380.

Rynes, S.L. (1991), "Recruitment, job choice, and post-hire consequences: a call for new research directions", in Dunnette, M.D. and Hough, L.M. (Eds), Handbook of Industrial and Organizational Psychology, 2nd ed., Vol. 2, Consulting Psychologist, Palo Alto, CA, pp. 399-444.

Salgado, J.F. and Moscoso, S. (2003), "Internet-based personality testing: equivalence of measures and assesses' perceptions and reactions", International Journal of Selection and Assessment, Vol. 11 Nos 2/3, pp. 194-205.

Sinar, E.F., Reynolds, D.H. and Paquet, S.L. (2003), "Nothing but 'net? Corporate image and web-based testing", International Journal of Selection and Assessment, Vol. 11 Nos 2/3, pp. 150-157.

Smith, G. (2018), The Al Delusion, Oxford University Press, Oxford.

Smurthwaite, C. (2019), "Trying to attract top talent? Make recruitment a game", available at: www. growwire.com/recruitment-games (accessed 7 May 2019).

Software Advice (2019), "Video interview software", available at: www.softwareadvice.com/hr/videointerviewing-comparison/ (accessed 5 May 2019).

Stone, D.L., Lukaszewski, K. and Isenhour, L.C. (2005), "E-recruiting: online strategies for attracting talent", in Gueutal, H.G. and Stone, D.L. (Eds), The Brave New World of eHR: Human Resources Management in the Digital Age, Jossey Bass, San Francisco, pp. 22-53.

Stone, D.L., Lukaszewski, K., Stone-Romero, E.F. and Johnson, T. (2013), "Factors affecting the acceptance and effectiveness of e-selection systems", Human Resource Management Review, Vol. 23 No. 1, pp. 50-70.

Stone, D.L., Stone-Romero, E.F. and Lukaszewski, K. (2003), "The functional and dysfunctional consequences of human resource information technology for organizations and their employees", in Stone, D. (Ed.), Advances in Human Performance and Cognitive Engineering Research, Vol. 3., Elsevier, pp. 37-68.

Strohmeier, S. (2007), "Research in e-HRM: review and implications", Human Resource Management Review, Vol. 17 No. 1, pp. 19-37.

Sturman, M.C., Hannon, J.M. and Milkovich, G.T. (1996), "Computerized decision aids for flexible benefits decisions: the effects of an expert system and decision support system on employee intentions and satisfaction with benefits", Personnel Psychology, Vol. 49 No. 4, pp. 883-908.

Sylva, H. and Mol, S.T. (2009), "E-recruitment: a study into applicant perceptions of an online application system", International Journal of Selection and Assessment, Vol. 17 No. 3, pp. 311-323.

Tian, X. and Pu, Y. (2008), "An artificial neural network approach to hotel employee satisfaction: the case of China”, Social Behavior and Personality: An International Journal, Vol. 36 No. 4, pp. 467-482.

Tippins, N.T., Beaty, J., Drasgow, F., Gibson, W.M., Pearlman, K., Segall, D.O. and Shepherd, W. (2006), "Unproctored internet testing in employment settings", Personnel Psychology, Vol. 59 No. 1, pp. 189-225.

Turing, A.M. (1950), "Computing machinery and intelligence”, Mind, Vol. LIX No. 236, pp. 433-460.

Vellenga, E. (2016), "A retention management research of the Amsterdam restaurant industry", Master's Thesis, University of Amsterdam, Amsterdam. 
Verquer, M.L., Beehr, T.A. and Wagner, S.H. (2003), "A meta-analysis of relations between person-organization fit and work attitudes", Journal of Vocational Behavior, Vol. 63 No. 3, pp. 473-489.

von Krogh, G. (2018), "Artificial intelligence in organizations: new opportunities for phenomenon-based theorizing", Academy of Management Discoveries, Vol. 4 No. 4, pp. 404-409.

Wanous, J.P. (1978), "Realistic job previews: can a procedure to reduce turnover also influence the relationship between abilities and performance? ", Personnel Psychology, Vol. 31 No. 2, pp. 249-258.

Workopolis (2016), "Why you absolutely must call every candidate back after an interview", available at: https://hiring.workopolis.com/article/why-you-absolutely-must-call-all-candidates-back-after-an-interview/ (accessed 10 May 2019).

Wright, A. (2017), "Top HR technology trends for 2018", available at: www.shrm.org/resourcesandtools/ hr-topics/technology/pages/top-hr-technology-trends-2018.aspx (accessed 6 May 2019).

Xiao, B. and Benbasat, I. (2007), "E-commerce product recommendation agents: use, characteristics, and impact", MIS Quarterly, Vol. 31 No. 1, pp. 137-209.

\section{Further reading}

PWC (2017), "Artificial intelligence in HR: a no-brainer", available at: www.pwc.at/de/publikationen/ verschiedenes/artificial-intelligence-in-hr-a-no-brainer.pdf (accessed 4 May 2019).

Raybould, M. and Wilkins, H. (2006), "Generic skills for hospitality management: a comparative study of management expectations and student perceptions", Journal of Hospitality and Tourism Management, Vol. 13 No. 2, pp. 177-188.

\section{Corresponding author}

Richard D. Johnson can be contacted at: richard.d.johnson@wsu.edu

For instructions on how to order reprints of this article, please visit our website: www.emeraldgrouppublishing.com/licensing/reprints.htm

Or contact us for further details: permissions@emeraldinsight.com 